\title{
Pollution Scenario due to discharge of effluent from Agrochemicals and Pesticides Manufacturing Industries of Dombivali Industrial Belt of Mumbai, India
}

\author{
P. U. Singare ${ }^{1, *}$, S. S. Dhabarde ${ }^{2,3}$ \\ ${ }^{1}$ Department of Chemistry, Bhavan's College, Munshi Nagar, Andheri (West), Mumbai, \\ Maharashtra 400058, India \\ ${ }^{2}$ Department of Chemistry, K.V. Pendharkar College, Dombivali (East), Dist. Thane, \\ Maharashtra 421201, India \\ ${ }^{3}$ Department of Chemistry, Pacific University of Higher Education \& Research University, \\ Udaipur, Rajasthan, India \\ *E-mail address: pravinsingare@gmail.com
}

\begin{abstract}
The paper deals with monitoring of pollution arising due to agrochemicals and pesticides manufacturing industries located along the Dombivali industrial belt of Mumbai, India. The study was carried for the period of one year from June, 2012 to May, 2013 to study the level of toxic heavy metals and the physico-chemical properties of waste water effluents discharged from the above industries. The average concentration of $\mathrm{Cu}, \mathrm{Ni}, \mathrm{Cr}, \mathrm{Pb}$ and $\mathrm{Zn}$ was found to be maximum of 29.86, $0.90,1.16$ and $1.19 \mathrm{ppm}$ respectively in summer season, while average Fe concentration was maximum of $51.10 \mathrm{ppm}$ in winter season. The average $\mathrm{pH}$ value of the effluent was found to be maximum of 12.95 in summer season, while average conductivity value was maximum of 21085 $\mu \mathrm{mhos} / \mathrm{cm}$ in rainy season. The majority of physco-chemical parameters like alkalinity, hardness, salinity, chloride, cyanide, phosphate, total solid, BOD and COD content were found to be maximum in summer season having the average values of 1918, 186, 4, 11.20, 0.07, 81, 6391, 685 and 2556 ppm respectively. The average DO content was found to be low of $4.5 \mathrm{ppm}$ in winter season. It was observed that the concentration level of majority of the toxic heavy metals and physico-chemical properties were above the tolerable limit set for inland surface water. The results of present study indicates that the existing situation if mishandled can cause irreparable ecological harm in the long term well masked by short term economic prosperity due to extensive industrial growth.
\end{abstract}

Keywords: industrial effluents; physico-chemical properties; heavy metals; agrochemicals; pesticides; Dombivali industrial belt; Mumbai

\section{INTRODUCTION}

The production of pesticides started in India in 1952 with the establishment of a plant for the production of $\mathrm{BHC}$ near Calcutta, and India is now the second largest manufacturer of pesticides in Asia after China and ranks twelfth globally [1]. There has been a steady growth in the production of technical grade pesticides in India, from 5,000 metric tons in 1958 to 
102,240 metric tons in 1998. The pattern of pesticide usage in India is different from that for the world in general. In India $76 \%$ of the pesticide used is insecticide, as against $44 \%$ globally [1]. The use of herbicides and fungicides is correspondingly less heavy. The main use of pesticides in India is for cotton crops (45\%), followed by paddy and wheat. It is estimated that about 380000 tons of pesticides and other halogenated hydrocarbons are used each year in India, of which 55000 tons are used in agriculture. The total of 107000 tons of DDT and its isomers are consumed per year [2]. According to one report, consumption of pesticide in the Indian Ocean region and neighbouring countries are as follows: 11000 tons in Pakistan, 3000 tons in Bangladesh and 28000 tons in Sri Lanka [3]. These chemicals are used as pesticides, herbicides and fungicides in agriculture and for controlling vector-borne diseases as malaria. It is recognized that a large portion of the pesticides used on land reaches the oceans through atmospheric transport and river discharge in India [4]. Groundwater pollution due to pesticides is a worldwide problem.

According to the USGS, at least 143 different pesticides and 21 transformation products have been found in ground water, including pesticides from every major chemical class. During one survey in India, $58 \%$ of drinking water samples drawn from various hand pumps and wells around Bhopal were contaminated with Organo Chlorine pesticides above the EPA standards [5]. Once ground water is polluted with toxic chemicals, it may take many years for the contamination to dissipate or be cleaned up. Cleanup may also be very costly and complex, if not impossible [6-8]. Pesticide/Agrochemical manufacturing industry wastewater poses pollution problems due to the toxic components, high chemical oxygen demand $(C O D)$, biochemical oxygen demand $(B O D)$; high Total dissolved solids $(T D S)$ and high alkaline $\mathrm{pH}$ in the range of 12-14. The most important portion of contamination due to this wastewater is observed in agricultural areas and in surface waters that come from agricultural areas. Major quality of pesticide pollution is released during pesticide manufacturing. Pesticide, usually have direct adverse effects on the living organisms.

Pesticides are highly toxic and carcinogenic in nature even at picogram loads [9]. Moreover it persists in nature for long period of time. The process of pesticide removal from the industrial wastewater is of great importance because of well-known pesticide resistance to microbial degradation and has tendency to bio-accumulate in the soil fauna and flora. Pesticides are carcinogenic and mutagenic in nature [10]. Pesticide wastewater distinguishes itself because of its toxic and persistent nature in the environment. This wastewater depicts wide variation in its characteristics based on the pesticide production; raw materials used and water consumption and wastewater flow [11,12]. Considering the environmental impact of agrochemicals and pesticides at global level, in the present investigation attempts was made to carry out the comprehensive survey of pollution arising due to such industries located in Dombivali MIDC industrial belt which is considered to be one of the most polluted industrial belts of Mumbai.

\section{EXPERIMENTAL}

\section{1. Study area}

The Dombivali industrial area was established by Maharashtra Industrial Development Corporation (M.I.D.C) in 1964. The industrial belt occupies an area of about 347.88 hector, is located in south of Ulhas River and about $45.00 \mathrm{~km}$ from Mumbai international airport. There are about 30 highly polluting small/ medium/ large scale chemical industries located in this industrial belt. Quantity of industrial effluent generated in the industrial area is about 14 
MLD, which is finally discharged into the creek through open drainages which was passing through residential area [13].

\section{2. Climatic condition}

Dombivali enjoys a tropical climate with mean annual temperature of $24.3^{\circ} \mathrm{C}$ (min) to $32.9^{\circ} \mathrm{C}$ (max). The hottest and driest part of the year is April-May, when temperature rises to $38.0{ }^{\circ} \mathrm{C}$. The humidity is usually in the range of 58 to $84 \%$ and sea breeze in the evening hours is a blessing to combat the high temperature and humidity during summer months. The average southwest monsoon rainfall is in the range of $1850 \mathrm{~mm}$ to $2000 \mathrm{~mm}$. The average annual rainfall in the region is the range from 1286 to $1233 \mathrm{~mm}$ [13].

\section{3. Requirements}

All the chemicals and reagent used for analysis were of analytical reagent grade. The glasswares used in the analysis were washed with distilled de-ionized water; the pipettes and burette were rinsed with the experimental solution before final use.

\section{4. Industrial Effluent Sampling and Preservation}

The industrial waste water effluent samples were collected randomly twice in a month in morning, afternoon and evening session from three representative agrochemicals and pesticides manufacturing units of Dombivali industrial belt of Mumbai. The samples were collected every month from June, 2012 to May, 2013. Polythene bottles of $2.5 \mathrm{~L}$ and $2.0 \mathrm{~L}$ were used to collect the grab water samples (number of samples collected, $n=20$ ). The bottles were thoroughly cleaned with hydrochloric acid, washed with tape water to render free of acid, washed with distilled water twice, again rinsed with the water sample to be collected and then filled up the bottle with the sample leaving only a small air gap at the top. The sample bottles were stoppard and sealed with paraffin wax.

\section{5. Physico-chemical Study}

The samples were collected were analyzed for $\mathrm{pH}$, conductivity, alkalinity, hardness, salinity, chloride, cyanide, phosphate content, Total Dissolved Solids (T.D.S), Total Suspended Solids (T.S.S), Total Solids (T.S), Dissolved Oxygen (D.O), Bio-chemical Oxygen Demand (B.O.D) and Chemical Oxygen Demand (C.O.D) values. The techniques and methods followed for collection, preservation, analysis and interpretation are those given by Rainwater and Thatcher [14], Brown et al. [15], I.C.M.R [16], Hem [17] and A.P.H.A [18].

\section{6. Heavy Metal Analysis by AAS Technique}

Water samples $(500 \mathrm{~mL})$ were filtered using Whatman No. $41(0.45 \mu \mathrm{m}$ pore size $)$ filter paper for estimation of dissolved metal content. Filtrate $(500 \mathrm{~mL})$ was preserved with $2 \mathrm{~mL}$ nitric acid to prevent the precipitation of metals. The samples were concentrated on a water bath depending on the suspected level of the metals [19].

The analysis for the majority of the trace metals like copper $(\mathrm{Cu})$, nickel $(\mathrm{Ni})$, chromium $(\mathrm{Cr})$, lead $(\mathrm{Pb})$, iron $(\mathrm{Fe})$ and zinc $(\mathrm{Zn})$ was done by Perkin Elmer ASS-280 Flame Atomic Absorption Spectrophotometer. The calibration curves were prepared separately for all the metals by running different concentrations of standard solutions. A reagent blank sample was run throughout the method, and the blank readings were subtracted from the 
samples to correct for reagent impurities and other sources of errors from the environment. Average values of three replicates were taken for each determination.

\section{RESULTS AND DISCUSSION}

The experimentally measured pollution data on heavy metal content and physicochemical properties of industrial waste water effluents released from agrochemicals and pesticides manufacturing industries located along the Dombivali industrial belt of Mumbai is presented in Tables 1 and 2.

Table 1. Heavy metal content in the effluents released from agrochemical industries located along Dombivali industrial belt of Mumbai, India.

\begin{tabular}{|c|c|c|c|c|c|c|c|c|c|c|c|c|c|c|c|}
\hline \multirow{2}{*}{ 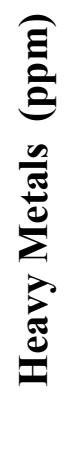 } & \multicolumn{5}{|c|}{ Rainy Season } & \multicolumn{5}{|c|}{ Winter Season } & \multicolumn{5}{|c|}{ Summer Season } \\
\hline & 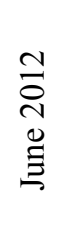 & $\begin{array}{l}\stackrel{1}{3} \\
\stackrel{N}{1} \\
\stackrel{2}{\Xi}\end{array}$ & 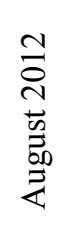 & 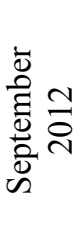 & 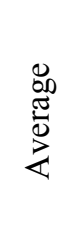 & 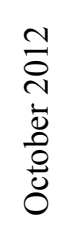 & 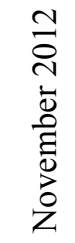 & 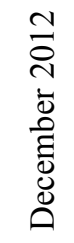 & 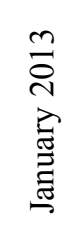 & 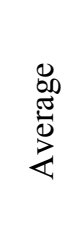 & 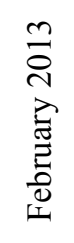 & 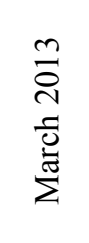 & $\begin{array}{l}m \\
\stackrel{2}{N} \\
\bar{\Xi} \\
\overrightarrow{0}\end{array}$ & 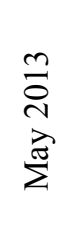 & 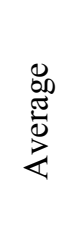 \\
\hline $\mathrm{Cu}$ & 0.68 & 0.78 & 0.96 & 1.87 & 1.07 & 5.88 & 8.35 & 14.45 & 19.54 & 12.06 & 30.58 & 29.67 & 28.68 & 30.52 & 29.86 \\
\hline $\mathrm{Ni}$ & 0.48 & 0.46 & 0.38 & 0.57 & 0.47 & 0.6 & 0.86 & 0.67 & 0.75 & 0.72 & 0.87 & 0.98 & 0.88 & 0.86 & 0.90 \\
\hline $\mathrm{Cr}$ & 0.52 & 0.5 & 0.37 & 0.54 & 0.48 & 0.55 & 0.76 & 0.99 & 1.09 & 0.85 & 1.12 & 1.2 & 1.16 & 1.15 & 1.16 \\
\hline $\mathrm{Pb}$ & 0.49 & 0.65 & 0.54 & 0.74 & 0.61 & 0.73 & 0.76 & 0.95 & 1.14 & 0.90 & 1.15 & 1.19 & 1.25 & 1.18 & 1.19 \\
\hline $\mathrm{Fe}$ & 0.2 & $\mid$\begin{tabular}{|l}
0.97 \\
\end{tabular} & 1.45 & 3.4 & 1.51 & 59.21 & 40.45 & 50.42 & 54.3 & 51.10 & 41.59 & 44.69 & 41.29 & 42.9 & 42.62 \\
\hline $\mathrm{Zn}$ & 0.59 & 0.87 & 1.06 & 0.95 & 0.87 & 2.58 & 4.54 & 5.23 & 3.86 & 4.05 & 6.27 & 5.59 & 6.74 & 6 & 6.15 \\
\hline
\end{tabular}

Trace elements are those elements which are present in relatively low concentration of less than few ppm. Among the special group of trace elements are the heavy metals which are having the potential to create health hazards among humans, plants and other aquatic biological life. Under the group of heavy metals are $\mathrm{Cr}, \mathrm{Ni}, \mathrm{Zn}, \mathrm{Cu}, \mathrm{Pb}$ and $\mathrm{Fe}$. They are classified under the group of heavy metals because in metallic form they have the densities higher than $4 \mathrm{~g} / \mathrm{cm}^{3}$. 
Table 2. Physico-chemical properties of the effluents released from agrochemical industries located along Dombivali industrial belt of Mumbai, India.

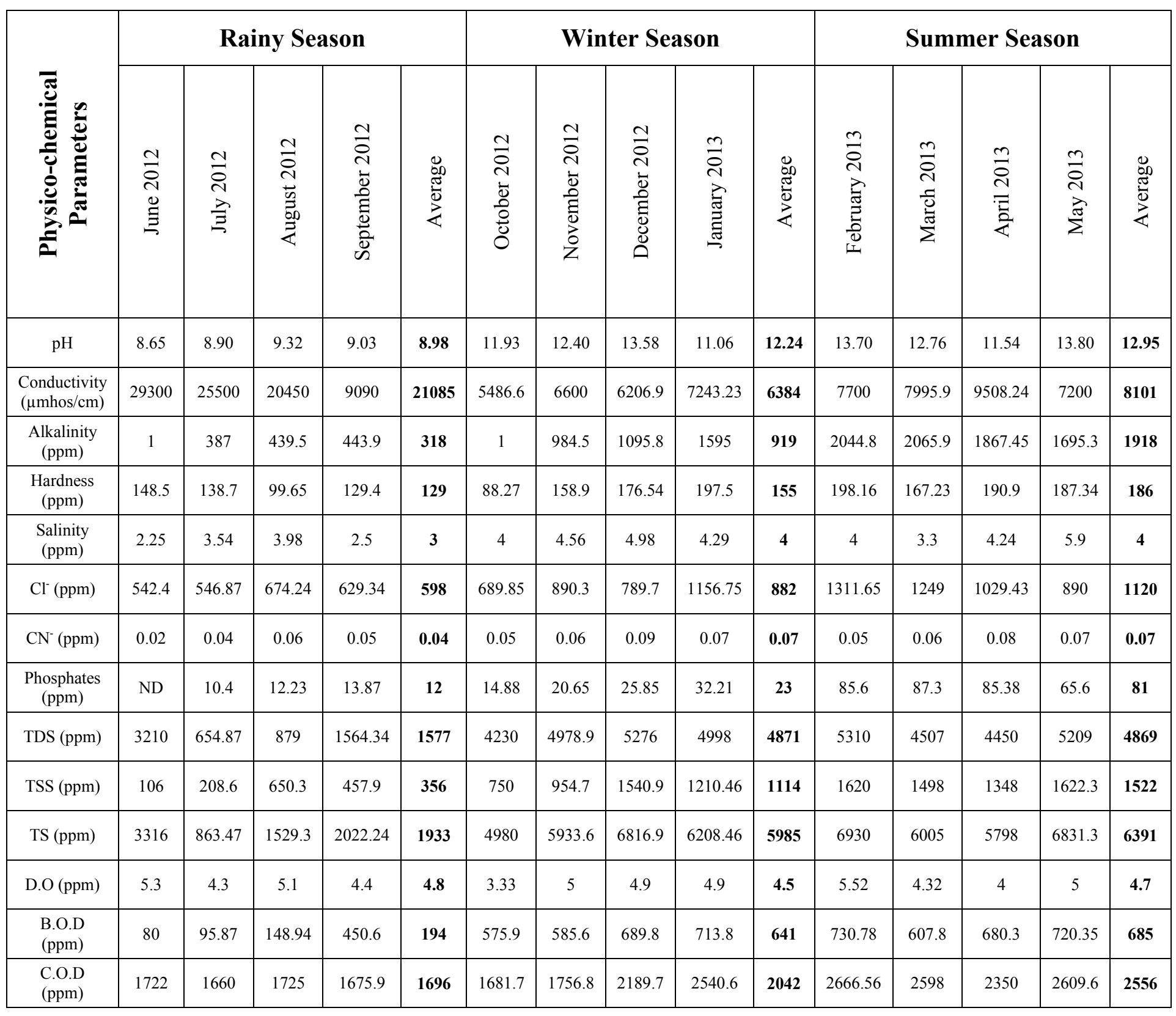

The average $\mathrm{Cu}$ content in the effluent samples collected was found to be minimum of $1.07 \mathrm{ppm}$ in rainy season which increases to $29.86 \mathrm{ppm}$ in summer season. The values reported were above the permissible limit of $0.05 \mathrm{ppm}$ set by W.H.O and $1.0 \mathrm{ppm}$ as per the USPH standards. The average $N i$ content in the waste water samples was found to vary between $0.47 \mathrm{ppm}$ in rainy season to $0.90 \mathrm{ppm}$ in summer. The overall experimental observed $\mathrm{Ni}$ concentration was above the maximum limit of $0.1 \mathrm{ppm}$ set by W.H.O. The average $\mathrm{Cr}$ content in the industrial effluent samples was found to vary between $0.48 \mathrm{ppm}$ in rainy season which was minimum to maximum of $1.16 \mathrm{ppm}$ in summer, which was higher than the maximum permissible limit of 0.05 ppm set by W.H.O [20]. 
The steady increase in concentration of $P b$ in the effluent samples was observed from $0.61 \mathrm{ppm}$ in rainy season to $1.19 \mathrm{ppm}$ in summer, which was extremely higher than the general standard limit of $0.1 \mathrm{ppm}$ lead set for effluents discharge in inland surface water [21]. The drastic increase in $\mathrm{Fe}$ concentration in the industrial waste water effluent was observed from $1.51 \mathrm{ppm}$ in rainy season to $51.10 \mathrm{ppm}$ in winter season, while in summer the $\mathrm{Fe}$ concentration was found to be $42.62 \mathrm{ppm}$.

The observed level of $\mathrm{Fe}$ in summer and winter seasons were above the permissible limit of $3.0 \mathrm{ppm}$ iron set for effluents discharge in inland surface water [21]. The concentration of $Z n$ in the industrial waste water effluent samples was in the range of 0.87 $\mathrm{ppm}$ in rainy season to $6.15 \mathrm{ppm}$ in summer season, while in winter the concentration of $Z n$ was found to be $4.05 \mathrm{ppm}$. The level of $Z n$ in the effluent samples collected in summer season was extremely higher than the general standard limit of $5.0 \mathrm{ppm} \mathrm{Zn}$ set for effluents discharge in inland surface water [21].

In any environmental monitoring study related to pollution of surface water, physicochemical parameters gives valuable information regarding the pollution load. It is found that most of the industries in India are located near the water bodies because of their extensive requirement of water for various industrial activities. The waste water from such industries are generally discharged in drainages which finally enter the nearby water bodies creating extensive pollution creating threat to the aquatic life and health of surrounding human population. The most common physico-chemical parameters are $\mathrm{pH}$, conductivity, hardness, alkalinity, suspended and dissolved solids, BOD, COD and DO.

These parameters generally decide the extent of pollution and help in planning the waste water treatment technology which is to be adopted. In the present investigation it was observed that the $\mathrm{pH}$ value was minimum of 8.98 in rainy, 12.24 in winter and 12.95 in summer season which was maximum. It is important here to note that the permissible $\mathrm{pH}$ range of inland surface water subjected to pollution load is 5.5 to 9.0 [21-31]. The average conductivity of the industrial waste water effluent was found to vary in the range of 6384 $\mu \mathrm{mhos} / \mathrm{cm}$ in winter to $21085 \mu \mathrm{mhos} / \mathrm{cm}$ in rainy season.

The majority of physco-chemical parameters like alkalinity, hardness, salinity, chloride, cyanide, phosphate, total solid, BOD and COD content in summer season were found to be maximum having the values of 1918, 186, 4.0, 11.20, 0.07, 81, 6391, 685 and $2556 \mathrm{ppm}$ respectively. The values of the above physico-chemical parameters were found to be minimum of $318,129,3.0,598,0.04,121933,194$ and $1696 \mathrm{ppm}$ respectively in rainy season. The DO content was found to be low of $4.5 \mathrm{ppm}$ in winter and high of $4.8 \mathrm{ppm}$ in rainy season.

\section{CONCLUSION}

The ecological and human health safety due to discharge of heavily polluted industrial effluents are undoubtedly under threat. The present experimental data on environmental risk assessment studies due to agrochemical and pesticides manufacturing industries may be regarded as an aid towards a better understanding of the problem arising due to such industries.

There is a need to convey the message that prevention of adverse health effects and promotion of health are profitable investments for employers and employees as a support to a sustainable development of economics. From the results of the present investigation it seems that the time has come to move towards ecosystem specific discharge standards to maintain 
the health and productivity of natural resources on which the majority of Indians are dependent. These are possible by proper treatment of effluent water and enforcement of pollution control by the regulatory authority on the indiscriminate discharge of industrial wastewater into water bodies should be carried out.

Educating the urban as well as the rural mass is another major step to put a check on such industrial pollution. Masses should be made aware of the drastic consequences of such industrial pollution on their lives, both directly and indirectly. The existing situation if mishandled can cause irreparable ecological harm in the long term well masked by short term economic prosperity due to extensive industrial growth.

\section{References}

[1] Mathur S. C., Pesticide Information 24(4) (1999) 9-23.

[2] Glasby G. P., Roonwal G. S., Curr. Sci. 68 (1995) 495-497.

[3] Qasim S. Z., J. Indian. Ocean. Stud. 9(3) (2001) 417-425.

[4] GESAMP. The atmospheric input of trace species to the world ocean. GESAMP, Rep. Stud. $1989 ; 38$.

[5] Kole R. K., Bagchi M. M., J. Inland Fish Soc. India. 27(2) (1995) 79-89.

[6] Waskom R., Best management practices for private well protection. 1994. Colorado State Univ. Cooperative Extension (August).

http://hermes.ecn.purdue.edu:8001/cgi/convertwq?7488.

[7] O'Neil W., Raucher R. Wayzata M. N., Groundwater Policy Education Project; 1998. Aug, Groundwater public policyleaflet series \#4: The costs of groundwater Contamination; http://www.dnr.state.wi.us/org/water/dwg/gw/costofgw.htm.

[8] US EPA. Water protection practices bulletin. Washington, DC: Office of Water; 2001. Jul, Managing small-scale application of pesticides to prevent contamination of drinking water. EPA 816-F-01-031.

[9] Anonymus, International Agency for Research on Cancer (IARC) Monographs, IARC, Lyon, France, Vol. 54, Suppl. 7 (1997) 40-51.

[10] S. Sahinkaya, C. Ozdemir, M. Karatas, Use of Fenton's Reagents for Removal of Pesticides from Industrial Wastewater, Modern Management of Mine Producing, Geology and Environmental Protection, SGEM-2007, Bulgaria, 1 (2007) 421-434.

[11] Balkrishnan R. B., Kamal Mohamed Seeni Meera, Perumal V., Removal of Pesticides by Electrochemical Methods- A Comparative Approach, Sustain. Environ. Res. 21(6) (2011) 401-406.

[12] Misra R., Shanta S., Potle N., International Journal of Chemical and Physical Sciences 2 (2013) 39-51.

[13] Action Plan for Industrial Cluster "Dombivali”, Maharashtra Pollution Control Board, November 2010. http://www.mpcb.gov.in

[14] Rainwater F. H., Thatcher L. L., U.S. Geol. Surv. Water Supply Papers 1454 (1960) $1-301$. 
[15] E. Brown M. W., Skougstad M. J. Fishman, 'Methods for collection and analysis of water samples for dissolved minerals and gases', Techniques of Water Resources Investigations of the U.S. Geological Survey Vol. 160, Book 5, Chapter A1 (1970)

[16] Indian Council of Medical Research (ICMR) Manual of Standards of Quality for Drinking Water Supplies, (1975)

[17] J. D. Hem, 'Study and Interpretation of Chemical Characteristics of Natural Water', 3rd ed., U.S. Geological Survey, Washington (1985)

[18] American Public Health Association (APHA), Standard Methods for Estimation of Water and Wastewater, 19th ed., American Water Works Association, Water Environment Federation, Washington, (1995).

[19] Chen M., Ma L. Q., Soil Science Society of American Journal 65(2) (2001) 491-499.

[20] A. K. De, Environmental Chemistry, pp. 232-272, 4th ed., New Age International (P) Ltd., New Delhi, India (2002).

[21] The Environment (Protection) Rules (1986), Available at: http://www.cpcb.nic.in/GeneralStandards.pdf (assessed on November 2011).

[22] P. Daniszewski, International Letters of Chemistry, Physics and Astronomy 4 (2012) 112-118.

[23] E. Cyrania, P. Daniszewski, B. Draszawka-Bołzan, International Letters of Chemistry, Physics and Astronomy 5 (2012) 96-103.

[24] E. Cyraniak, P. Daniszewski, B. Draszawka-Bołzan, International Letters of Chemistry, Physics and Astronomy 5 (2012) 88-95.

[25] P. Daniszewski, R. Konieczny, International Letters of Chemistry, Physics and Astronomy 4 (2013) 91-97.

[26] P. Daniszewski, R. Konieczny, International Letters of Chemistry, Physics and Astronomy 4 (2013) 98-104.

[27] P. U. Singare, M. S. Talpade, D. V. Dagli, V. G. Bhawe, International Letters of Chemistry, Physics and Astronomy 8(2) (2013) 94-104

[28] P. U. Singare, M. S. Talpade, D. V. Dagli, V. G. Bhawe, International Letters of Chemistry, Physics and Astronomy 8(2) (2013) 105-112

[29] P. Daniszewski, International Letters of Chemistry, Physics and Astronomy 8(3) (2013) 269-278.

[30] P. Daniszewski, International Letters of Chemistry, Physics and Astronomy 8(3) (2013) 279-287.

[31] P. Daniszewski, International Letters of Chemistry, Physics and Astronomy 10(2) (2013) 218-226. 